Rev. Fac. Med. vet. Zootec. Univ. S. Paulo, $13(2): 309-15,1976$

\title{
COMPORTAMENTO DE BEZERROS HOLANDESES EM AMBIENTES NATURAL E AQUECIDO
}

\author{
Carlos de Sousa LUCCI * \\ Enoch Borges de OIIVEIRA FILHO * \\ Noc MASOTII * \\ Esleibe GHION **
}

\begin{tabular}{|l|}
\hline RFMV-A 21 \\
\hline
\end{tabular}

Lucci, C. DE S.; Otiveira Filho, E.B. DE: MAsotTi, N: GHios, E. Comportamento de bezerros holandeses em ambientes natural e aquecido. Rev. Fae. Med. vet. Zootec. Univ. S. Paulo, 13(2):309-15. 1976.

RESUMo: Dozc bezerros machos Holandeses com 5 meses de idade foram utilizados em 2 tratamentos: a) ambiente natural e b) camara climática. A cámara cra ligada diariamente das 13 às 17 horas, mantendo temperatura aproximada de $30{ }^{\circ}$. Os consumos de alimentos volumosos, fornecidos ad libitum, e os ganhos ae peso foram semelhantes ao fim de 64 dias de experimentacio. As temperaturas internas foram algo maiores, mas nāo significativamente maiores e as freqüências respiratórias foram significativamente maiores para os bezerros dentro da câmara climatica.

LnITERmos: Bezerros"; Câmara climática*; Termoregulaçāo*.

\section{INTRODUCÃO}

Uma questão frequentemente levantada em Zootecnia é a dos efeitos da tomperatura e umidade ambientes sobre a ingestão de alimentos por parte de bovinos de raças européias. DAVIS e MERILAN 5, trabalhando com vacas leiteiras, registraram um decréscimo no consumo de alimentos em temperaturas ambientes elevadas. OLBRICH 9 e ou. tros colocaram animais de 19 meses cie idade sob temperatura de $31^{\prime \prime C}$. A concentração de ácidos graxos voláteis totais no liquido ruminal decresceu sig. nificativamente devido a menor quantidade de alimentos ingeridos e ao maior consumo de água.

O fato que os animais reduzem a ingestão de alimentos quando colocados sob temperaturas elevadas fundamentou a teoria termostática de regulação do apetite (CHURCH 4 ). A menor ingestão de alimentos é secundária a processos de dissipação de calor. Por exemplo, AL-

Professor Livre-Docente.

* Plofessur Assistente.

* Professor Assistente Doutor.

Departamento de Produçāo Animal da Faculdade de Medicina Veterinária e Zootecnica da USP. 
BRIGHT e ALLISTON 1 em amplo levantamento sobre variações ambientais que possam alterar o desempenho de bovinos leiteiros, explicam que com o aumento da temperatura, inicialmente há captação dessa variação do meio por receptores cutâneos, os quais desencadeiam processos reflexos vasomotores e sudomotores. Se este tipo de controle se mostrar inadequado, outro mecanismo de defesa, via cerebral, é acionado para intensificar as reações iniciais visando perda de calor.

Em se tratando de bezerros o assunto é dos mais interessantes em virtude da maior sensibilidade dos animais novos às agressões climáticas externas. KRDZAI.IC, MARINAC e AZANJAC 8 trabalhan. clo com bezerros de 1 a 15 dias de idade, determinaram que grandes flutuaçōes da temperatura e umidade relativa durante um dia resultam em altas porcentagens de doenças e mortes desses animais. BIANCA e HALES:3 compararam bezerros racém-nascidos e com 1 ano de idade, quando expostos por 210 minutos a temperaturas de $15^{\circ}$ a $50^{\circ} \mathrm{C}$. Embora as temperaturas retais fossem significativamente menores nos recém-nascidos, oevido provavelmente a suas maiores capacidades de sudorese por unidade de peso metabólico, suas frequências respiratórias foram maiores, sugerindo maior sensibilidade ao calor. ROY ${ }^{13}$ e outros submetendo bezerros ruminantes e préruminantes a temperaturas de $21^{\prime \prime}$ e $14,5^{\circ} \mathrm{C}$, descobriu que os ruminantes apresentam maior sensibilidade ao frio.

O bezerro produz calor como resultante: a) de seu metabolismo nasal, b) de sua atividade voluntária, c) da con. versão de alimentos em tecido corporal e d) da atividade fermentativa do rúmen, no caso dos ruminantes. Por outro lado, a dissipação das quantidades excessivas de calor ocorre por convecção e radiação de sua temperatura corporal (produção de calor sensivel) e ainda por evaporação da umidade da pele e do trato respiratório (perda de calor por evaporação).
Se a temperatura ambiznte for muito clcvada, essas vias de dissipaçāo podem não ser suficientes, mssmo com o recurso auxiliar da taquipnea. Neste caso, só resta a alternativa de diminuir a ingestão de alimentos, reduzindose desta maneira a produção de calor (ROY 12). Além da redução do consumo de alimentos, diminuem as atividades fisioló. gicas em geral. ATTEBERY e JOHNSON 2 fornecendo quantidades de alimentos fixas e iguais para vacas leiteiras, submeteu-as à temperaturas de $29^{\prime \prime} \mathrm{C}$, $35)^{\circ} \mathrm{C}$ e $38^{\circ} \mathrm{C}$ respectivamente, por 2,2 c 5 dias seguidos. Com a exposição mais demorada à temperatura de $38^{\circ} \mathrm{C}$, surgiu um decréscimo significativo na amplitude das contrações ruminais. GANGWAR 6, relata que durante o desconforto causado por temperaturas elevadas, a produção do hormónio de crescimento pela pituitária anterior é deprimida, bem como outras atividades fisiológicas, necessárias para o pleno desenvolvimento do animal, até que este se adapte por completo ao ambiente. A adaptação só foi notada após 60 dias de exposição ao calor, em novilhas Holstein - Friesian.

Naturalmente, menores ingestões de alimentos significam pior desempenho. KAMAL e JOHNSON 7 colocaram 6 bezerros Frisios de 6 meses de idade em uma câmara climática, durante 3 dias, a temperatura de $32,2^{\prime \prime} \mathrm{C}$. O calor causou perda de $15 \%$ em sólidos totais do corpo e como o balanço do nitrogênio mostrou. se positivo, essa perda foi atribuida ao tecido adiposo.

$\mathrm{Na}$ atualidade, os nutricionistas vem recomendando processos de desaleita. mento precoce. com uso intenso de pastagens por bezerros de idades novas. As pastagens do Brasil-central tem o máximo de produção ocorrendo de outubro a março, justamente o periodo mais quente do ano (PEDREIRA 10). O presente estudo constituiu um esforço em se tomar contacto com possíveis alterações no consumo de alimentos, nas frequências respiratórias e temperaturas 
internas de bezerros Holandeses submetidos a curtas exposiçŏes de calor, em câmara climática.

\section{MATERIAL E MÉTODOS}

As observaçōes foram conduzidas no CIZIP, em Pirs.ssununga-SP., de 14/3/1975 a 16/5/1975, a uma altitude de $634 \mathrm{~m}$, 21'> 59' latitude sul e $47^{\prime \prime} 59^{\prime}$ longitude oeste.

Foram utilizados 12 bezerros machos inteiros Holandeses ppc malhados de preto, com idade aproximada de $5 \mathrm{me}$ ses ao inicio do trabalho, em um delincamento de blocos ao acaso segundo PIMENTEL GOMES "1, formando-se 6 fures de animais submetidos a 2 tratamentos: a) ambiente natural e b) cámara climática.

O lote no tratamento $A$ ficou alojado em abrigo coberto, em baias individuais de $2,0 \mathrm{~m} \times 1,5 \mathrm{~m}$, providas de estrados de madeira sobre piso de concreto. As pa$r \in d e s$ laterais eram formadas de réguas de madeira, permitindo ampla ventilaç̃̃o.

O lote no tratamento $B$ permaneceu dentro dè uma câmara climática. em baias individuais de $2,0 \mathrm{~m} \times 1,5 \mathrm{~m}$, também providas de estrados de madeira.

A câmara era ligada diariamente por 4 horas seguidas, das $13 \mathrm{~h}$ às $17 \mathrm{~h}$ e fora deste periodo permanecia desligada e com as portas abertas para entrada de ar exterior. A renovaçāo de ar, devido ao tamanho e localizaçāo das portas, era muito lenta.

O arraçoamento e manejo dos bezerros foi identico para ambos os tratamentos. Forneceu-se diariamente $2,5 \mathrm{~kg}$ por animal de uma mistura concentrada com $25^{\circ} \%$ de farelo de soja, $74 \%$ de espigas de milho desintegrado e $1 \%$ de sal mineralisado. Como alimento volumoso ofertou-se "ad libitum" o capim Irapier (Pennisetum purpureum), colhido no mesmo dia e picado no momento da refeição. O controle do consumo indi. vidual (pisitgem das ofertas e sobras) foi feita diariamente. $\mathrm{O}$ experimento durou 64 cias, sendo o capim retirado sempre de uma mesma área, suficiente para permitir manejo adequado da capineira: os cortes foram realizados com a graminea apresentando alturas entre $0,6 \mathrm{~m}$ a $1,0 \mathrm{~m}$.

Os animais foram pesados semanalmente, sempre no mesmo horário, pila manhã.

As temperaturas e a umidade am. biente foram registradas todos os dias, às $17,00 \mathrm{~h}$, quando a câmara era desligada. Para temperatura foram usados termômetros de mercúrio "Berse", de máxima e minima e para umidade, higrômetros de cabelo "Sundo".

Em 23 dias não consecutivos, duran. tc a experimentação, foram tomadas as temperaturas retais de cada bezerro, deixando-se o bulbo do tərmômetro em contacto com a mucosa pelo tempo mínimo de 2 minutos, e contados os movimentos respiratórios no intervalo de 1 minuto. Essas medidas foram tomadas às $17,00 \mathrm{~h}$.

De início, fixou-se o teor de $70 \%$ de umidade relativa do ar e temporatura de $30^{\circ} \mathrm{C}$ como valores a serem obtidos dentro da câmara climática, quando colocada em funcionamento (das $13,00 \mathrm{~h}$ às $17,00 \mathrm{~h}$ ).

\section{RESULTADOS}

O consumo de alimentos concentrados foi sempre rápido e total. por todos os animais, nāo ocorrendo sobras. Esta foi realmente a intençāo dos AA., de que os animais ingerissem concentrados em quantidades suficientes para garantir um crescimento normal, sem prejuizos maiores para o consumo do volumoso, fornecido a vontade. O consumo do ca. pim, como média diária por individuo 
(matéria original) foi de $10,3 \mathrm{~kg}$ no ambiente e $10,7 \mathrm{~kg}$ na câmara. O coeficiente de variação foi igual a $10,6 \%$, conside- rado baixo. A análise de variância das ingestões de capim Napier é apresentada no Quadro I.

Quadro 1 - Análise de variância das ingestões de capim Napier

\begin{tabular}{lcccr}
\hline Fontes de varlaçóo & $\begin{array}{c}\text { Gíaus de } \\
\text { Liberdade }\end{array}$ & $\begin{array}{c}\text { Soma dos } \\
\text { Qundrados }\end{array}$ & $\begin{array}{c}\text { Quadrados } \\
\text { Médios }\end{array}$ \\
\hline Tratamentos & 1 & 0.44 & 0.44 & 0.36 \\
Blocos & 5 & 16.06 & 3.21 & 1.23 \\
Residuo & 5 & 6.15 & 22.61 \\
Total & 11 & 2.65 &
\end{tabular}

Os ganhos de peso foram iguais a $0,674 \mathrm{~kg}$. respectivamente. O coeficiente $44,6 \mathrm{~kg}$ por bezerro no ambiente, e de variação foi elevado, igual a $27,1 \%$. $43,2 \mathrm{~kg}$ por bezerro na câmara, corres- A análise de variância dos ganhos de peso pondendo a ganhos diários de $0,697 \mathrm{~kg}$ e é apresentada no Quadro 2:

Quadro 2 - Análise de variância dos ganhos de peso individuais, em quilogramas

\begin{tabular}{lcccc}
\hline Fontes de variação & $\begin{array}{c}\text { Graus de } \\
\text { Liberdade }\end{array}$ & $\begin{array}{c}\text { Soma dos } \\
\text { Quadridos }\end{array}$ & $\begin{array}{c}\text { Quadrados } \\
\text { Médios }\end{array}$ & $F$ \\
\hline Tratamentos & 1 & 6,02 & 6.02 & 0.04 \\
Blocos & 5 & 238.93 & 47.79 & 0.33 \\
Residuo & 5 & 709.11 & 141.82 & \\
Total & 11 & 954.06 &
\end{tabular}

As temperaturas internas, tomadas na mucosa do reto foram analisadas para as 23 tomadas em cada animal, obtendo-se resultados médios individuais de $40,1^{\circ} \mathrm{C}$ no ambiente, contra $40,6^{\circ} \mathrm{C}$ na câmara. O coeficiente de variação foi muito baixo, igubl a $1,2 \%$ e a análise de variância é apresentada no Quadro 3 , onde não foi constatada diferença significativa entre tratamentos.

Quadro 3 - Análise de variância das temperaturas médias internas por bezerro, em ${ }^{\circ} \mathrm{C}$.

\begin{tabular}{|c|c|c|c|c|}
\hline Fontes de varlaçăo & $\begin{array}{l}\text { Graus de } \\
\text { Llberdade }\end{array}$ & $\begin{array}{l}\text { Soma dos } \\
\text { Quadrados }\end{array}$ & $\begin{array}{l}\text { Quadrados } \\
\text { Medilos }\end{array}$ & $\mathbf{F}$ \\
\hline Tratamentos & 1 & 0.80 & 0.80 & 3,23 \\
\hline Blocos & 5 & 0,61 & 0,12 & 0.48 \\
\hline Resíduo & 5 & 1.24 & 0.25 & \\
\hline Total & 11 & 2,65 & & \\
\hline
\end{tabular}


As frequências dos movimentos respiratórios por minuto foram analisaclos usando-se as 23 contagens para cada animal, obtendo-se resultados médios individuais de 64 no ambiente, contra 94 na câmara. O coeficiente de variação foi muito baixo, igual a $1,9 \%$ e a análise de variância, apresentada no Quadro 4, constatou ser significativa a diferenç? entre tratamentos.

Ruadro 4 - Análise de variância das frequências respiratórias, em movimentos por minuto.

\begin{tabular}{lcccc}
\hline Fontes de variação & $\begin{array}{l}\text { Graus de } \\
\text { Liberdade }\end{array}$ & $\begin{array}{c}\text { Soma dos } \\
\text { Quadrados }\end{array}$ & $\begin{array}{c}\text { Quadrados } \\
\text { Médíos }\end{array}$ & F \\
\hline Tratamentos & 1 & 2670 & 2670 & $11.85\left(^{\circ}\right)$ \\
Blocos & 5 & 1399 & 280 & 1,24 \\
Residuo & 5 & 1125 & 225 & \\
Total & 11 & 5194 & & \\
\hline
\end{tabular}

(*) - significativo no nivel de $5 \%$ de probabilidade.

As temperaturas, em graus centigrados, e as unidades relativas, em porcentagens, são fornecidas no Quadro 5 para o ambiente externo e para a Câmara cli- mática, como médias dos 23 dias nos quais se coletaram temperaturas retais e frequências respiratórias.

Quadro 5 - Temperatura ambiente em graus centigrados e umidade relativa do ar, em porcentagem

\begin{tabular}{|c|c|c|c|c|c|}
\hline \multirow[b]{2}{*}{ Mês } & \multirow{2}{*}{$\begin{array}{l}\text { N. }{ }^{\circ} \text { de } \\
\text { coletas }\end{array}$} & \multicolumn{2}{|c|}{ Temperatura local } & \multicolumn{2}{|c|}{ Umidade local } \\
\hline & & Ambiente & Câmara & Ambiente & Câmara \\
\hline Março & 6 & $29.4^{\circ}$ & $30.6^{\circ}$ & $68.3 \%$ & $70.2 \%$ \\
\hline Abril & 14 & $26.2^{\circ}$ & $29.5^{\circ}$ & $61.4 \%$ & $66.5 \%$ \\
\hline Maio & 3 & $26.0^{\circ}$ & $30.0^{\circ}$ & $52,3 \%$ & $62.3 \%$ \\
\hline
\end{tabular}

\section{DISCUSSĀO}

Não houve diminuição do consumo de alimentos por parte dos bezerros colocados na câmara climática, ao contrário dos resultados de DAVIS e MERILAN" e OLBRICH 9 e outros. No entanto, os mecanismos de dissipação térmica, principalmente, os de perda por evaporação (ROY 12) poderiam ser suficientes para atender a homeotermia dos ar.imais, não havendo necessidade de recorrer a processos de redução do calor produzido, como a menor ingestão.

Além dos consumos terem sido semelhantes, os ganhos de peso também foram idênticos, de onde se entende que as conversōes de nutrientes em tecido corporal e a atividade fermentativa do rúmen não sofreram alterações notáveis em termos de produção animal. ATTE- 
BERY e JOHNSON : também não notaram modificaçōes das contrações do rúmen até $35^{\circ} \mathrm{C}$ de temperatura, com vacas ingerindo a mesma quantidade de alimsntos. Da mesma forma não ocorreram neste estudo quaisquer alterações fisiológicas dos relatados por GANG. WAR 6, que pudessem interferir no crescimento dos bezerros. Quanto ao mecanismo de produção de calor por atividade voluntária foi uma variável praticamente nula uma vez que os animais permaneciam confinados em baias de tamanho bastante reduzidon am qual quer dos tratamentos. Finalmente, podesé compreender pela observação do Quadro 2 quз, apesar do nümero de graus de liberdade do resíduo ser inde. sejavelmente pequeno (PIMENTEL GOMES 11) não houve qualqusr tendência para o efeito dos tratamentos ser considerado significativo.

As medidas de temperatura interna e da frequência dos movim»ntos respiratórios mostraram diferenças entre os 2 lotes de bezerros, sendo maiores após a exposição ao calor, na câmara climática. As temperaturas internas nảo mostraram diferenças estatisticamente significativas (Quadro 3) mas é possivel que o pequeno numero de repetiçōes tenha influido nesse resultado, já que a variância dos tratamentos é notavelments maior que a do resíduo. As frequências rsspiratórias foram significativamente maiorcs para o lote na cámara, demons. trando reação fisiológica a aplicação de temperaturas elevadas.

Embora os dados aqui obtidos se constituam um primeiro contacto com o problema de adaptação de bezerros ao calor, tudo indica que a exposição desses animais a temperaturas elevadas $\left(05^{\circ} \mathrm{C}\right)$ por curto período de tempo (4 horas por dia) provocou rzaçōes fisiologicas voltadas para uma maior dissipação térmica, não chegando a alterar os processos de formação de calor orgânico descritos por ROY 12. Resta saber em qual ponto em termos de tempera tura e/ ou período de exposição, seriam acionados os mecanismos secundários de diminuição do calor produzido.

\section{CONCLUSÖES}

Nas condiçōes do experimento, foi possível emitir as seguintes conclusões:

1. a) Nāo ocorreram efeitos da aplicação de temperaturas elevadas, em câmara climática, no consumo de alimentos e ganhos de peso por parte de bezerros.

2.a) As temperaturas internas de bezerros após cxposiçāo térmica na câmara climática foram maiores, e as frequências respiratórias significativamente maiores que a de seus pares fora da câmara.

RFMV-A 21

Lucci, C. de S.; Oliveira Filho, E. B. de; MasotT. N.; Ghios, E. Bchaviout of Ho'stein calves at normal and heated environments. Rev. Fac. Mcd. vet. Zootec. Univ. S. Paulo, 13(2):309-15, 1976.

SUMMARY: Twelve Holstein male calves, 5 months old, were used for two trcatments: A) normal cnvironment and B) climatic chamber. Climatic chamber was put on daily form 1 to 5 p.m., with a temperature of $30^{\circ} \mathrm{C}$. Roughage consumptions and uright gains were similar after 64 days of observations. Rectal temfcratures uere higher but not significantly and respiratory rate were signicantly higher in climatic chambcr calves.

UNITERMS: Calves": Climatic chamber": Thermoregulation". 
1 - ALLBRIGHT, J. L. \& ALLISTON, C. W. Effects of varying the environment upon the performance of dairy cattle. J. Anim. Sci., 32:566-77, 1971

2 ATTEBERY, J. ' $\Gamma$. \& JOHNSON, H. D. Effects of environmental temperature, controlled feeding and fasting on rumen motillty. J. Anim. Sci., 29:73437. 1969 .

3 - BIANCA. W. \& HALES, J.R.S. Swenting, panting and body temperatures of newborn and one year old calves at high environmental temperatures. Brit. vet. J., 126:45-53, 1970

4 -- CHURCH, D. C. Digestive physiology and nutrition of ruminants. Corvallis, The O.S. U. Bookstores, 1972. v. 2.

5 -- DAVIS. A. V. \& MERILAN, C. P. Effect of constant environmental temperature and relative humidities on feed digestion of lactating Holstein cows. J. Dairy Sci. 43:871 (Resumo).

6 - GANGWAR, P. C. The effect of environmental temperature on growth of dairy helfers. Indian vet. J., 47:128-36, 1970 .

7 - KAMAL, T. H. \& JOHNSON, H. D. TOtal body sollds loss as a mensure of short-terms heat stress in cattle. $J$. Anim. Sci., 32:306-11, 1971.

8 - KRDZAZIC, P.: MARINAC, M.; AZANJAC. $N$. The influence of certain ecologic elements on the appearance of gastro intestinal diseascs in calves reared industrialy with special consideration of temperature and relative hum!dity. Prax, vet., 22(1/2):5966. 1974.

9 -- OLBRICH, S. E.: MARTZ, F. A.; JOHNSON, H. D.; PHILLIPS, S. W.; LIPPINCOTT, A. C.; HILDEBR,AND. E. S. Effect of constant ambient temperatures of $100 \mathrm{C}$ and $31^{\circ} \mathrm{C}$ on ruminal responses of cold tclerant and hoat tolerant sattle. J. Anim. Sct, 34(1): c4-9, 1972 .

$10 \ldots$ PFDREIRA. J. V.S. Crescimento estacional dos capins coloniāo. gordura. jeraguá e pangola. Taiwan A-24. Boletim Industria Animal, 30(1):59, 1973.

11 - PIMENTEL GOMES, F. Curso de estatistica experimental. 3 ed. Piracicaba. Escola Superior de Agricultura "Luiz de Queiróz", U. S. P.. 1972.

12 - ROY, J. H. B. The calf. London, Fermer \& Stockbreeder, 1970. v. 1

13 - ROY. J. H. B.: STOBO. I. J. F.; GASTON, H. J.; GANDERTON, P.; SHOTTON, M. The effect of environmental temperature on the performance and bealth of the pre-ruminant and ruminant calf. Brit. J. Nutr., 26(3): 363-81, 1971.

Recebido para publicaçảo em 27-7-76 Aprovado para publicaçāo em 13-9-76 